\title{
Enflasyon Vergisi Üzerine Bir Analiz: KKTC Örneği
}

\section{An Analysis On Inflation Tax: TRNC Case Study}

Soley AKÇABA ${ }^{\text {a, }}$, Prof. Dr. Okan Veli ŞAFAKLI ${ }^{\text {b }}$

${ }^{a}$ Dr. Öğr. Üyesi Lefke Avrupa Üniversitesi Lisansüstü Eğitim Öğretim ve Araştırma Enstitüsü İşletme Doktora Programı, Lefke 99728, KKTC. ORCID: 0000-0002-7546-9386

${ }^{\text {b }}$ Prof. Dr., Lefke Avrupa Üniversitesi, İktisadi ve İdari Bilimler Fakültesi, Bankacılık ve Finans Bölümü, Lefke 99728, KKTC ORCID: 0000-0001-9608-0217

\section{MAKALE BİLGİSI}

\section{Makale Geçmişi:}

Başvuru tarihi: 31 Mayıs 2019

Düzeltme tarihi: 20 Ekim 2019

Kabul tarihi: 01 Kasım 2019

\section{Anahtar Kelimeler:}

Senyoraj

Enflasyon Vergisi

Dolarizasyon

Para Arzı

KKTC

\section{A R T I CLE INFO}

\section{Article history:}

Received 31 May 2019

Received in revised form 20 October 2019

Accepted 01 November 2019

Keywords:

Seigniorage

Inflation tax

Dollarization

Money Supply

TRNC
ÖZ

Senyoraj, paranın üretim maliyetiyle üzerindeki yazılı değer arasındaki farktır. Senyoraj geliri, devletin para basma hakkını elinde bulundurması neticesinde elde ettiği gelirdir. Enflasyon vergisi ise, enflasyon sebebiyle elinde para tutanların uğradıkları sermaye kaybıdır. Kuzey Kıbrıs Türk Cumhuriyeti Merkez Bankası'nın emisyon yetkisi bulunmaması nedeniyle resmi para birimi olarak Türk Lirası'nı kullanması dolarizasyon kavramı olarak tanımlanır. Emisyon gücüne sahip olan taraf para arzı ile senyoraj geliri elde ederken, dolarizasyonu uygulayan taraf ise dolaşımdaki paranın satın alma gücünün reel olarak azalması sebebiyle enflasyon vergisine maruz kalır. Bu çalışma ile; Kuzey Kıbrıs Türk Cumhuriyeti’nin Türk Lirası kullanımı nedeniyle maruz kaldığı düşünülen enflasyon vergisini yıllar itibariyle incelenmiş, ortaya çıkan bulguları, Türkiye Cumhuriyeti'nin aynı süreç içerisinde KKTC'ye yapmış olduğu yardım miktarı ile karşılaştırmak suretiyle durum analizi yapılmıştır.

\section{A B S T R A C T}

Seigniorage is the difference between the value of the money and production cost. Seigniorage income is what the Government earns via its right to print money. Inflation tax is the loss of capital, due to inflation, of those who keep cash with themselves. The use of Turkish Lira (TRY) as official currency of Turkish Republic of Northern Cyprus (TRNC), because of the lack of emission authority of the Central Bank of TRNC can be classified as dollarization. While the party with emission authority earns seigniorage income, the other party is subjected to inflation tax due to loss in purchasing power of money in circulation. The aim of this study is to investigate the inflation tax that TRNC has been exposed to due to the use of TRY and to compare this with the aid received from Republic of Turkey in the same time frame.

\section{Giriş}

Kuzey Kıbrıs Türk Cumhuriyeti (KKTC) ekonomisinde özellikle yüksek döviz kurlarına bağlı dalgalanmaların ve yüksek enflasyon oranlarının yaşandığı, dolayısıyla halkın alım gücünün düştüğü bazı zamanlarda, kamuoyunda senyoraj, dolarizasyon ve enflasyon vergisi gibi kavramlar tartışılır duruma gelebilmektedir. Bunun nedeni yaşanılan enflasyon süreci ile ülkedeki toplam arzın toplam talebi karşılayamamasıyla birlikte kullanılan paranın değer kaybetmesi ve bu durumun fiyatlar genel düzeyinin devaml surette yükselmesine yol açmasıdır. Böyle zamanlar ülkedeki istikrarı bozmakla birlikte, uzun dönemde

\footnotetext{
* Sorumlu yazar/Corresponding author.

e-posta: soley@akcaba.com
} 
ekonomik kalkınmayı da olumsuz etkilemektedir (Öner, 1994).

Tedavüle giren paranın satın alma gücü ile paranın basılma maliyeti arasındaki fark senyoraj olarak adlandırılır. Genel anlamda ise senyoraj, paranın üretim maliyeti ile üzerinde yazılı değer arasındaki farktır. Meydana gelen bu fark devletin emisyon işlemi sonrasında kendi kasasına gelir olarak girer. $\mathrm{Bu}$ gelir senyoraj geliri olarak tanımlanır. Üretim karşılığı olmaksızın elde edilen bu gelir, üretilmiş mal hizmetlere karşılıksız ortak olunması anlamına gelmektedir. Piyasada dolaşımda bulunan para ise, paranın arzı ile belli bir oranda değer kaybetmektedir. Bu durum, kişilerin ellerindeki paranın satın alma gücünün tıpkı devlete vergi vermeleri durumundaki gibi azalmasına yol açar. $\mathrm{Bu}$ azalma miktarı ise enflasyon vergisine eşittir.

Eğer bir yerli para başka bir yabancı paranın kullanımı ile paranın hesap birimi olma, ödeme aracı olma ve paranın değer saklama gibi işlevlerini yerine getiriyorsa bu durum dolarizasyon olarak tanımlanır (Özen, 2018) Joint Economic Committee Staff Report'unda (1999), dolarizasyon olgusu çeşitlere ayrılmaktadır. Bunlar gayri resmi dolarizasyon, yarı resmi dolarizasyon ve resmi dolarizasyon olmak üzere üç çeşittir (Schuler, 1999). KKTC Merkez Bankası'nın emisyon faaliyeti bulunmaması nedeniyle resmi para birimi olarak Türk Lirası'nı seçmesi resmi dolarizasyon ya da tam dolarizasyon kavramı olarak tanımlanabilir. Çünkü KKTC'de TL yani yabancı para yasal olarak özel ve hâkim statüde olup, hükümet tarafından dolaşımdaki TL yasal anlamda hesap birimi olarak kabul etmektedir ve aynı zamanda ödemelerde kullanılmaktadır.

Resmi olarak dolarize olmuş bir ülke, parasını kullandığ ülke ile birleşik bir para alanının parçası durumuna gelmiştir. Gelişmekte olan ülkelerde sıkça görülen olgulardan bazıları, yüksek enflasyon ve parasal konulardaki problemlerdir. Bu kapsamdaki ülkeler istikrarlı ve güvenli ekonomilere sahip diğer ülkelerin paralarını kullanmayı tercih ederek kendilerini bu tür tehlikelerden bertaraf edebilirler. Çünkü normal koşullarda, resmi olarak dolarize olunan yabancı ülkenin parasında ekonomik ve yapısal problemler sıkça görülmemektedir (Özen, 2018). Öte yandan resmi dolarizasyonun ekonominin korunmasını garanti etmediği unutulmamalıdır. Örneğin parası tercih edilen ülkeyi ilgilendiren bir siyasi kriz, dolarize olmuş ülkenin ekonomisini de olumsuz etkiler. Bununla birlikte Edwards'a (2001) göre, dengesiz diş ticaret hadleri olan, önemli ekonomilerle derinlemesine entegre olmayan ülke ekonomilerinin dolarize olmaları halinde ciddi maliyetlere maruz kalınacağı, dişsal şoklarla baş etmede zorluk çekileceği ileri sürülerek dolarizasyonun benimsenmesi doğru değildir. Bu nedenle yüksek enflasyon dönemlerinde KKTC'de tartışma yaratan görüş, emisyon gücüne sahip olan tarafın para arzı ile senyoraj geliri elde ettiği, dolarizasyonu uygulayan tarafın ise dolaşımdaki paranın satın alma gücünün reel olarak azalması sebebiyle enflasyon vergisine maruz kaldığı şeklindedir.
Öte yandan, Türkiye Cumhuriyeti, KKTC'nin varoluş mücadelesinde maddi ve manevi katkılarıyla KKTC devletinin her daim yanı başında yer almıştır. KKTC ekonomisin büyümesi ve kendi ayakları üzerinde durabilmesi için çok uzun yıllardan bu yana kesintisiz hibe ve kredi yardımında bulunmaktadır (Bozkurt Gazetesi, 1959).

Çalışmanın amacı, 2002 yılından günümüze değin yıllar bazında KKTC ekonomisinin maruz kaldığı düşünülen enflasyon vergisi miktarlarını hesaplamak, bu verileri aynı yıllar itibariyle TC'den gelen yardım miktarları ile karşılaştırmak ve bulunan verileri GSYIH içindeki payları oranında inceleyerek analiz etmektir.

KKTC ekonomisinin dolaşımdaki para, vadesiz ticari mevduatlar, vadesiz tasarruf mevduatları ve Merkez Bankası mevduatları karşılıklarını kısaca M1para arzının, piyasada ki yüksek enflasyon ve döviz kuru nedeniyle yaşanan sermaye kayıplarının enflasyon vergisi miktarı olarak düşünülmüştür.

Çalışmada Bailey (1956), Friedman (1971) ve Phelps'in (1973) yapmış olduğu çalışmalarda enflasyon vergisi hesaplamalarına yönelik ana tanımlardan faydalanılmıştır. Ayrıca Türkiye'deki enflasyon vergisine ilişkin yapılan çalışmalarda Yıldırım (1996) ve Sönmez'in (1993) kullandığı hesaplama şekli irdelenmiştir. Obstfeld, (2012) ve Ferrer'ün (2012) gelişmiş analiz yöntemleri ile ulaştıkları enflasyon vergisine ilişkin sonuç da incelenmiștir. Bununla birlikte bu çalışma sonucu KKTC'deki enflasyon vergisine ait bulgular, Besim'in (2019) çalışma kağıdında yer alan aynı yıllardaki bulgular ile karşılaştırılmıştır.

KKTC yazılı basında bazı akademisyenler nadir zamanlarda, maruz kalındığı düşünülen enflasyon vergisinin yarattığı negatif etkileri yüksek sesle dillendirse dahi, literatürde KKTC ekonomisindeki enflasyon vergisine ait hesaplanmış bir bulguya rastlanmamıştır. Çalışmada, enflasyon vergisi ve parasal yardım miktarlarının GSYIH içindeki paylarına göre bulunan verilerin aynı platformda sunulması, yapılabilecek tartışma ve analizler için sağlıklı bir veri tabanı oluşturacaktır.

KKTC yazılı basında bazı akademisyenler nadir zamanlarda, maruz kalındığı düşünülen enflasyon vergisinin yarattığ negatif etkileri yüksek sesle dillendirse dahi, literatürde KKTC ekonomisindeki enflasyon vergisine ait hesaplanmış bir bulguya rastlanmamıştır. Çalışmada, enflasyon vergisi ve parasal yardım miktarlarının GSYIH içindeki paylarına göre bulunan verilerin aynı platformda sunulması, yapılabilecek tartışma ve analizler için sağlıklı bir veri tabanı oluşturacaktır.

\section{Yöntem}

Gelişmekte olan ülkelerde olduğu gibi KKTC'de de en önemli ekonomik göstergelerin başında enflasyon olgusu yer almaktadır. Bu olgu büyüme, işsizlik gibi ekonomik performansı etkilemede büyük rol almaktadır. 
Monetarist yaklaşımda senyoraj, devletin hükümdarlık hakkını kullanması ve bu yolla gelir elde etmesidir. Ampirik çalışmalarda senyoraj parasal tabandaki değişmenin tüketici fiyat endeksine oranı şeklinde ölçülendirilmektedir ( $\square \mathrm{M} / \mathrm{P})$ (Haan, Zelhorst, \& Roukens, 1993). Ancak karıştırılmaması gereken bir husus senyoraj gelirinin enflasyon gelirine eşit olmadığıdır.

Bailey (1956), enflasyon vergisini enflasyon oranının reel parasal tabanla çarpımı olarak tanımlamaktadır. Benzer şekilde Friedman, (1971) ve Phelps, (1973) yaptığ çalışmalarda da enflasyon vergisini enflasyon sebebiyle para tutanların uğradıkları sermaye kaybı ve dolayısıyla aşağıdaki gibi enflasyon oranıyla reel para balanslarının çarpımı şeklinde ifade edilmektedir.

$$
\begin{aligned}
& \text { Enflasyon Vergisi }=\pi *(M / P)(1) \\
& \pi=\text { enflasyon oranı } \\
& (\mathrm{M} / \mathrm{P})=\text { reel para arzı }
\end{aligned}
$$

Türkiye'de ki enflasyon vergisinin hesaplanmasına ilişkin yapılan bir çalışmada (Yıldırım, 1996), kamu açıklarının enflasyonist finansmanında enflasyon vergisini hesaplamak için reel balanslar ile enflasyon oranının çarpımından hareket edilerek, Türkiye'de ki enflasyon vergisini hesaplamış ve bulunan değerlerin GSMH içindeki payına dikkat çekilmiştir.

Bu çalışmada Obstfeld, (2012) ve Ferrer'ün (2012) gelişmiş analiz yöntemlerinden yararlanılmıştır. Buna göre reel toplam senyoraj tanımı şöyle ifade edilmektedir:

$$
\begin{aligned}
& S_{t}=S_{p}+\pi \text { vergisi }_{t}(2) \\
& S_{p}=p \text { fiyatındaki senyoraj } \\
& \pi \text { vergisi } i_{t}=t \text { zamanındaki enflasyon vergisi }
\end{aligned}
$$

eşitliği anlamlaştırmak amacıyla Ahumada, Gonzalez ve Alveredo'ün (2000) çalışmalarından yararlanılmış ve buna göre toplam senyoraj kavramı aşağıdaki gibi ifade edilmiştir.

$$
S_{t}=\Delta M_{t} / P_{t}=\left(M_{t}-M_{t-1}\right) / P_{t}
$$

Burada:

$$
\begin{gathered}
S_{t}=t \text { zamanındaki senyoraj } \\
M_{t}=\text { nominal para arzl }
\end{gathered}
$$

$$
P_{t}=t \text { zamanindaki fiyatlar genel seviyesini }
$$

$P_{t-1}=t-1$ zamanındaki fiyatlar genel seviyesini ifade etmektedir. Eğer,

$m_{t}=\Delta M_{t} / P_{t}$ t zamanında reel para arzı ve

$m_{t-1}=M_{t-1} / P_{t-1} t-1$ zamanında reel para arz1

olarak düşünülürse (3) deki aşağıdaki gibi yazılabilir:
$S_{t}=\Delta M_{t} / P_{t}=M_{t} / P_{t}-\left(M_{t-1} / P_{t-1}\right)\left(P_{t-1} / P_{t}\right)=$ $m_{t}-m_{t-1}\left(P_{t-1} / P_{t}\right)(4)$

$m_{t-1}$ 'in (4) toplama ve çıkarılması ile:

$S_{t}=m_{t}-m_{t-1}+m_{t-1}\left(1-P_{t-1} / P_{t}\right)(5)$

Ĕger enflasyon oranı, $\pi=\left(P_{t}-P_{t-1} / P_{t-1}\right)$ olarak verilirse (5)' deki eşitlik

$S_{t}=\Delta M_{t} / P_{t}=m_{t}-m_{t-1}+m_{t-1}\left(\pi / 1+\pi_{t}\right)$

olacaktır. (6)

Görüldüğü üzere senyoraj geliri iki farklı verinin toplamından elde edilmektedir. Birincisi devlet tarafindan enflasyondan etkilenmemiş para miktarındaki değişimi ifade eder ikincisi ise fiyatların değişim göstermesiyle sabit olan reel balanslardaki artışı yani enflasyon vergisini tanımlar.

Obstfeld'e (2012) göre ise, aynı eşitlik sürekli zaman için düşünülür ise, sadece $t$ zamanındaki senyoraj geliri aşağıdaki şekilde basite indirgenebilir.

$S_{t}=\Delta M_{t} / P_{t}=\pi_{t} m_{t}+\Delta m_{t}(7)$

$\mathrm{Bu}$ eşitlikte enflasyon vergisi sadece enflasyon oranı çarpı para arzıdır. ( $\square$. m ). Literatürde, Türkiye'de bütçe harcamalarına ilişkin IX. Türkiye Maliye Sempozyumu'nda Bütçe Açıklarının Finansmanı ve Enflasyon isimli çalışmada da enflasyon vergisine ait bulgular benzer yaklaşımla elde edilmiştir (Sönmez,1993). Aynı şekilde bu çalışmada elde edilen son iki yıla ait bulgular Besim'e (2019) ait çalışma raporundaki yöntemle uyumluluk göstermektedir.

\section{Yönetme İlişkin Kavramlar}

\subsection{Para Arzı (M1) ve Yabanc1 Para (YP)}

Ekonomide dolaşımdaki mevcut para miktarı para arzı olarak ifade edilir (Ünsal, 2000). Literatürde M harfi ile gösterilen para arzı darlıktan genişliğe doğru sıralanmak üzere farklı içeriklere sahiptir. Bu içerikler ülkeden ülkeye çeşitlilik gösterse dahi yaklaşım aynıdır. KKTC Merkez Bankası para arzını M1, M2 ve M3 olarak tanımlamaktadır. Buna göre,

M1 = Dolaşımdaki Para + Vadesiz Ticari Mevduat + Vadesiz Tasarruf Mevduatı + Vadesiz Diğer Mevduat + KKTC MB'deki mevduattır (KKTC MB, 2019).

Ekinci'ye (2003) göre likidite oranı en yüksek para arzı tanımı M1'dir ve dar tanımlı para arzı olarak nitelendirilir. Bugünün para stoku, M1 adı verilen parasal toplamdan oluşmaktadır. Kamu dolaşımındaki nakit para ve vadesiz mevduatı içerir. Yani cari hesaplardaki madeni para, banknot ve vadesiz mevduatı (diğer bankaların mevduatları dahil ) para olarak adlandırılır. Çünkü bu kalemler düzenli ödemelerin yapılmasında doğrudan transfer edilebilecek tam likiditeyi temsil etmektedir. Dolayısıyla, senyoraj ve enflasyon vergisi için referans olan para miktarı bugünün M1'dir (Huber, 2000). Bu nedenle çalışmada piyasada dolaşan para arzı olarak M1 değerinin kullanılması uygun görülmüştür. 
Yabancı para, ülke ekonomi piyasasında kullanılan her çeşit yabancı ülke parasına verilen isimdir. KKTC ekonomisinde ağırlıklı olarak kullanılan yabancı para birimleri başta Sterlin olmak üzere Euro ve Dolardır. Hesaplamalarda M1 miktarından, vadesiz yabancı para miktarı çıkarılmıştır. Çalışmada doğru sonuçlara ulaşabilmek için M1 para arzı miktarlarından YP vadesiz miktarları çıkarılmıştır (DPÖ, 2019). Yine y1llar itibariyle hesaplamalarda kullanılan M1 para arzı değerleri, enflasyondan arındırılmış M1 reel para arzı değerleridir.

\subsection{Enflasyon Oranı}

Enflasyon bir ekonomideki mal ve hizmetlerin fiyatlarında gözlenen sürekli ve genel kapsamlı artışı ifade etmektedir. Enflasyon oranının yüksek olması ekonomik büyümeyi olumsuz etkileyerek gelir dağılımını bozar, ekonomik dalgalanmalara neden olur ve işgücü piyasasının negatif yönde etkilenmesini sağlar (TCMB, 2013). Çalışmada enflasyon vergisinin hesaplanması amaciyla reel para balansları ile çarpılan enflasyon oranları, yıl sonu itibariyle oluşmuş Tüketici Fiyatları Endeksi (TÜFE) değerlerdir (DPÖ, 2019).

\subsection{Türkiye Cumhuriyeti Yardımları}

TC hükümetleri, KKTC ekonomisinin güçlenmesi ve refah seviyesinin artması için, uzun yıllardan bu yana maddi ve manevi katkı sağlamaktadır (Bozkurt Gazetesi, 1959). 1963 'de yaşanan vahim olaylar ve 1974'e kadar Kıbrıs Türkü'nün ağır baskılar altında yaşamını idame ettirme süreçlerinde de bu yardımlar kesintisiz devam etmiştir. Özellikle 1974'ten itibaren KKTC ile TC arasında çok yakın ekonomik ilişkiler kurulmuştur ve aynı para birimi kullanılmaya başlanmıştır. 2001 yılından itibaren KKTC ekonomisinin kendi kendine yeter hale gelebilmesi ve altyapısını sağlam temeller üzerine oturtabilmesi amacıyla ekonomik programlar uygulamaya konulmuş, bu itibarla her iki ülke arasında Ekonomik ve Mali İşbirliği Protokolleri imzalanmaya başlanmıştır. TC'den her yıl KKTC'ye yüksek miktarlarda yardım yapılmaktadır (Kendirci, 2013). Bu yardımlar kredi ve hibe olarak sınıflanmasına karşın, çalışmada toplam yardım miktarları kullanılmıştır. Bunun nedeni kredi katkı miktarlarının da faizsiz, geri ödemesiz hibe niteliğinde olmasıdır (KEİ, 2019)

\subsection{Gayrisafi Yurt. İçi Hasıla ( GSYİH)}

Ekonomide, belirli bir zamanda üretilen mal ve hizmetlerin toplam değeri GSYİH'yi vermektedir. Çalışmada elde edilen bulgular GSYİH içindeki paylarına göre düzenlenmiştir. Bunun nedeni, GSYİH'nin ekonomik faaliyetlerin genel düzeyini göstermesi bakımından en çok kullanılan kavram olmasıdır (Yükseler, 1998). Cari fiyatlarla GSYİH değerleri Devlet Planlama Örgütü (DPÖ) resmi internet sitesinden alınmıştır (DPÖ, 2019)

\section{Bulgular}

Çalışmada, 2002- 2018 dönemini kapsayan enflasyon vergisi ve TC yardımları yıllık bazda incelenmiştir. Çalışmada aylar itibariyle gerçekleşen TÜFE verileri sonucu oluşan enflasyon oranı ile, reel para balansı çarpılarak enflasyon vergisi hesaplanmıştır. Bulgular GSYİH içindeki paylarına göre karşılaştırılmıştır. Çalışmada Devlet Planlama Örgütü, KKTC Merkez Bankası ve TC Kalkınma ve İşbirliği Ofisi internet sayfasından elde edilen veriler kullanılmıştır. Buna göre

Enflasyon Vergisi $=\square(\mathrm{t}) * \mathrm{~m}(\mathrm{t})(8)$ Enflasyon oranı ile reel para balanslarının çarpımı

$$
\begin{gathered}
\pi=\text { Enflasyon oranı } \\
m=M 1(9) \\
M 1(T L)=M 1-Y P(10)
\end{gathered}
$$

Enflasyon Vergisi $=\pi *(M 1(T L) /(1+\pi))$

\begin{tabular}{|c|c|c|c|c|c|}
\hline Y11 & $\begin{array}{c}\text { M1 } \\
(\mathrm{Bin} T L)\end{array}$ & $\begin{array}{l}\text { YP } \\
\text { Vadesiz } \\
\text { (Bin TL) }\end{array}$ & $\pi$ & $\begin{array}{c}\text { M1(TL) } \\
\text { Reel } \\
\text { (Bin TL) }\end{array}$ & H \\
\hline 2002 & 8.1 & 159.973 & $24,50 \%$ & 110.981 & 1.407 .701 \\
\hline 2003 & 424 & 3 & $\%$ & 67 & 1.877 .403 \\
\hline 2004 & 618.443 & 359.067 & $11,60 \%$ & 232.416 & 2.456 .744 \\
\hline 2005 & 695.902 & 85 & $70 \%$ & 352 & 3.070 .380 \\
\hline 2006 & 845. & 3 & $19,20 \%$ & 385 & 3.988 .099 \\
\hline 2007 & 859.501 & 38 & $40 \%$ & 462 & 4.604 .292 \\
\hline 2008 & 898.452 & 348.900 & $14,50 \%$ & 479.958 & 5.079 .907 \\
\hline 2009 & 1.152 .252 & 469.000 & $5,70 \%$ & 646.407 & 5.376 .318 \\
\hline 2010 & 1.174 .045 & 524.900 & $3,27 \%$ & 628.590 & 5.614 .136 \\
\hline 2011 & 1.560 .706 & 652.900 & $14,72 \%$ & 791.323 & 6.508 .996 \\
\hline 2012 & 1.661 .192 & 692.500 & $3,60 \%$ & 935.031 & 6.955 .084 \\
\hline 2013 & 1.963 .378 & 988.100 & $10,22 \%$ & 884.847 & 7.606 .898 \\
\hline 2014 & 2.210 .968 & 671.529 & $6,49 \%$ & 1.445 .618 & 8.858 .586 \\
\hline 2015 & 2.84 & 11 & $78 \%$ & 1.71 & 10.222 .4 \\
\hline 2016 & 3.544 .115 & 1.271 .387 & $10,19 \%$ & 2.062 .554 & 11.601 .2 \\
\hline 2017 & 4.403 .294 & 1.705 .780 & $14,68 \%$ & 2.352 .210 & 14.544 \\
\hline 2018 & .520 .7 & 262 & 96 & 2.500 .379 & 8. \\
\hline
\end{tabular}

Tablo 1: 2002-2018 Temel Göstergeler

Kaynak: (DPÖ, 2019; KKTC MB, 2019)

$\mathrm{Bu}$ çalışmada KKTC'deki enflasyon vergisi 2002 yılı itibariyle hesaplanmıştır. Çünkü KKTC Merkez Bankası bu tarih itibariyle M1 verilerini yayınlamaya başlamıştır (Tablo $1)$. 
Tablo 2: Enflasyon Vergisi ve TC Yardımları GSYIH İçindeki Payları

\begin{tabular}{|c|c|c|c|c|}
\hline Y1l & $\begin{array}{c}\text { Enflasyon } \\
\text { Vergisi } \\
(\text { Bin TL) }\end{array}$ & $\begin{array}{c}\text { TC } \\
\text { Yardimı } \\
\text { (Bin } \\
\text { TL) }\end{array}$ & $\begin{array}{c}\text { Enf.Verg./ } \\
\text { GSYİH } \\
(\%)\end{array}$ & $\begin{array}{c}\text { TC } \\
\text { Yard./ } \\
\text { GSYİH } \\
(\%)\end{array}$ \\
\hline 2002 & 27.190 & 424.999 & 1,93 & 30,19 \\
\hline 2003 & 21.618 & 432.054 & 1,15 & 23,01 \\
\hline 2004 & 26.960 & 345.357 & 1,10 & 14,06 \\
\hline 2005 & 9.517 & 516.110 & 0,31 & 16,81 \\
\hline 2006 & 74.026 & 627.583 & 1,86 & 15,74 \\
\hline 2007 & 43.431 & 564.556 & 0,94 & 12,26 \\
\hline 2008 & 69.594 & 750.300 & 1,37 & 14,77 \\
\hline 2009 & 36.845 & 928.690 & 0,69 & 17,27 \\
\hline 2010 & 20.555 & 867.072 & 0,37 & 15,44 \\
\hline 2011 & 116.483 & 838.129 & 1,79 & 12,88 \\
\hline 2012 & 33.661 & 803.997 & 0,48 & 11,56 \\
\hline 2013 & 90.431 & 928.381 & 1,19 & 12,20 \\
\hline 2014 & 93.821 & 893.047 & 1,06 & 10,08 \\
\hline 2015 & 133.320 & 820.384 & 1,30 & 8,03 \\
\hline 2016 & 210.174 & 726.280 & 1,81 & 6,26 \\
\hline 2017 & 345.304 & 930.651 & 2,37 & 6,40 \\
\hline 2018 & 749.113 & 486.000 & 4,02 & 2,61 \\
\hline & & \multicolumn{3}{|c|}{$\begin{array}{l}* 1 \text { milyar } 654 \\
\text { milyon TL } \\
\text { bütçelendi }\end{array}$} \\
\hline
\end{tabular}

Kaynak: (DPÖ, 2019; KKTC MB, 2019)

Enflasyon vergisi ve TC yardımları Tablo 2'de yer almaktadır. Aynı tabloda elde edilen bulguların GSYİH içindeki payları da görülmektedir. Rakamsal olarak incelendiği zaman enflasyon vergisinin 2002-2018 döneminin son yıllarında bir artış yaşamıştır ancak GSYIH içindeki payları oranında incelendiği zaman ise enflasyon vergisinin belli sınırlar içinde seyir izlediği anlaşılmaktadır. Bununla birlikte enflasyon vergisinde 2018 yılında belirgin bir artış olduğu gözlenmektedir. Aynı tabloda TC yardımları rakamsal olarak incelendiğinde, her yıl istikrarlı bir artışın olduğu, TC yardımların GSYİH içindeki paylarına göre ise azalan bir seyir izlediği özellikle 2014 sonrası daha hızlı düşme eğiliminde olduğu görülmektedir. Ancak temel bulgular GSYİH içindeki payları nispetinde karşılaştırıldığında TC yardımları oranlarının, enflasyon vergisi oranlarından kat kat yüksek olduğu görülmüştür.
Tablo 2'de yer alan rakamsal bulgular daha iyi analiz edilebilmesine olanak sağlanması açısından aşağıda Şekil 1 ortamına taşınmıştır.

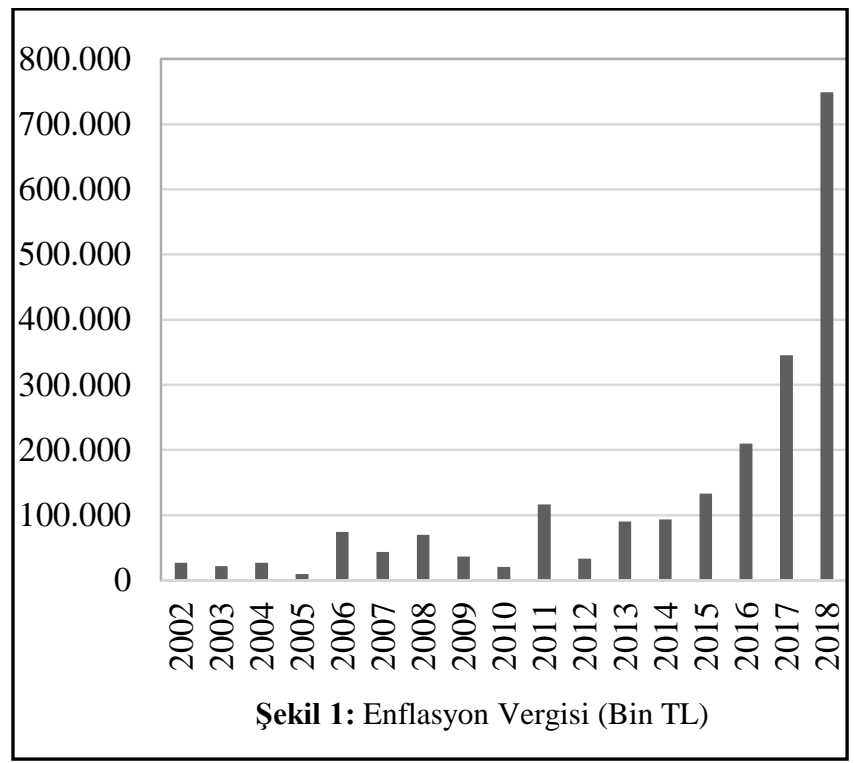

Kaynak : (DPÖ, 2019; KKTC MB, 2019)

KKTC'de enflasyon vergisi miktarı 2002-2013 yılları aras1 genelde istikrarlı bir yapı izlemiştir. Ancak 2013 yılından sonra enflasyon vergisi miktarının artma eğiliminde olduğu ve özellikle 2018 yılında gerçekleşen enflasyon değerinin çok yüksek olması nedeniyle, ulaşılan değerde keskin bir artışın olduğu görülmüştür (Şekil 1)

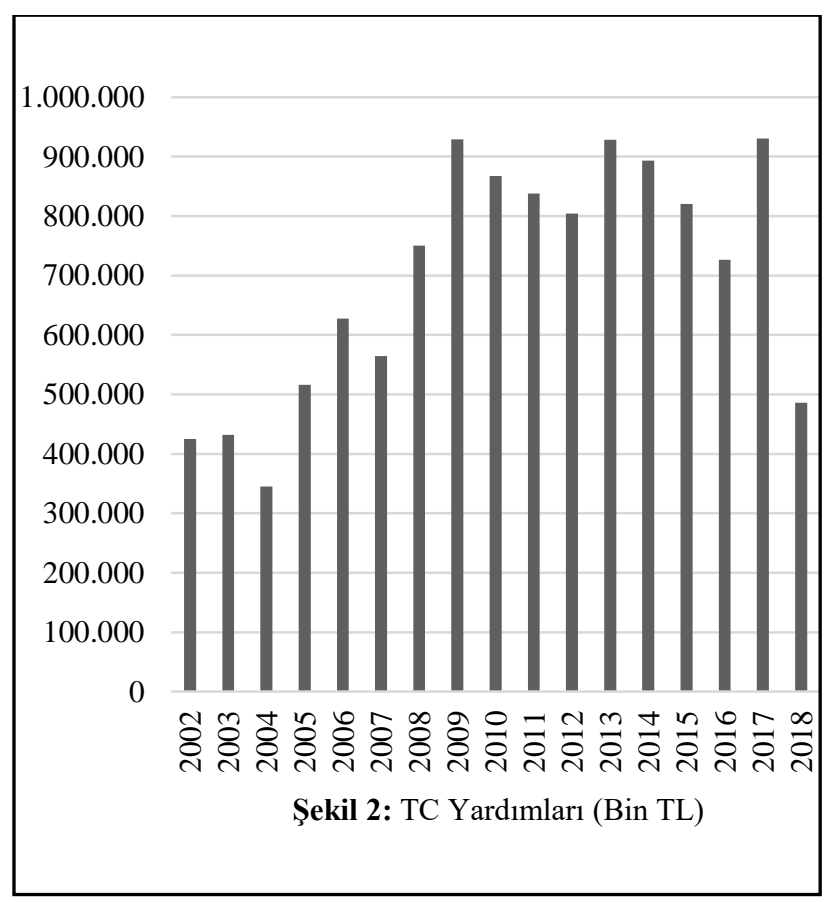

Kaynak: (DPÖ, 2019; KKTC MB, 2019)

TC yardımları KKTC ekonomisinin büyümesinde ve kalkınmasında çok önemli rol oynamaktadır. 1974 öncesinde başlayan dönemlerden bu yana düzenli olarak her y1l KKTC bütçesine yapılan katkılardan yalnızca 2002-2018 yıllarına ait dönemdeki katkılar Şekil 2' de yer almaktadır. Hibe ve krediler toplamından oluşan yardımların yıllar itibariyle düzenli artış seyrettiği saptanmıştır. Her ne kadar 2018 yılı 
yardım miktarında bir azalış görülse dahi bunun sebebi aslında bütçeye konulan katkı miktarının 1 milyar 654 milyon TL olmasına rağmen sadece 486 milyon TL'sinin kullanıma verilmiş olmasıdır (Besim, 2019).

KKTC'de enflasyon vergisinin GSYİH içindeki payı aynı yıllarda yapılan TC yardımlarının GSYİH içindeki payından oldukça düşüktür. Özellikle bu fark 2002-2003 yılları arasında TC yardım miktarının GSYİH içindeki payları oranı, enflasyon vergisinin GSYİH içindeki payları oranının ortalama 17 katıdır. 2004-20014 y1lları arasında ise ortalama 14 kattır (Şekil 3).

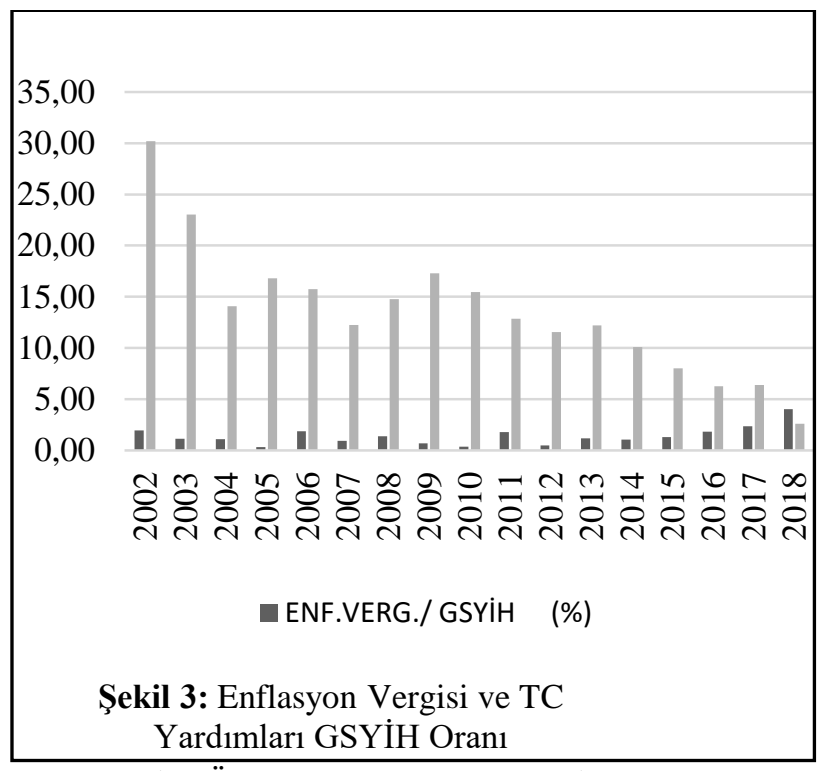

Kaynak: (DPÖ, 2019; KKTC MB, 2019)

\section{Sonuç}

KKTC'de yaşanan ekonomik kriz dönemlerinde senyoraj, dolarizasyon ve enflasyon kavramları kamuoyunda tartışılır duruma gelmekte, bu konulara ilgiyi artırmaktadır. Ülkede kullanılan ve kabul edilen resmi para birimi TL'dir. Bu olay literatüre göre dolarizasyon olarak tanımlanmaktadır. Merkez bankalarının emisyon işlemleri sonucunda, işlem hacmine sahip ülkelerin kendi kasasına giren para senyoraj geliridir. Ancak KKTC Merkez Bankası'nın emisyon faaliyeti bulunmamaktadır. Senyoraj geliriyle bir taraf gelir kazanırken, diğer taraf yani piyasada dolaşımda bulunan paraya sahip olanlar, paranın değer kaybı ile bir çeşit sermaye kaybı yaşamaktadır. Piyasada dolaşımdaki paranın satın alma gücündeki azalma enflasyon vergisi olarak nitelendirilmektedir.

KKTC ekonomisi, enflasyon oranlarının yükseldiği dönemlerde dolarizasyonun etkisiyle artan enflasyon vergisi miktarından olumsuz etkilenmektedir. Ancak diğer yandan, TC hükümetleri tarafından KKTC'ye, ekonominin büyüme ve kalkınması için 1974 öncesinden bu yana kesintisiz devam eden, önemli miktarlarda para yardımı bulunmaktadır.
Bu çalışmada enflasyon vergisi hesaplanırken Bailey (1956), Friedman (1971) ve Phelps'in (1973) yapmış olduğu çalışmalardaki ana tanımlardan yararlanılmıştır. Ayrıca Türkiye'deki enflasyon vergisine ilişkin Yıldırım (1996) ve Sönmez'in (1993) çalışmalarında başvurduğu hesaplama şekli ve Obstfeld, (2012) ile Ferrer'ün (2012) gelişmiş analiz yöntemleri ile ulaştıkları sonuçta da aynı hesaplama şekline vurgu yapılmaktadır. Bununla birlikte bu çalışma ile elde edilen KKTC'deki enflasyon vergisine ait veriler, Besim'in (2019) çalışma kağıdında yer alan yıllardaki veriler ile birebir örtüşmektedir.

Çalışma, KKTC'de 2002-2018 yılları arasında oluşan enflasyon vergisi miktarları ile aynı yıllarda TC'den gelen hibe ve kredilerden oluşan toplam parasal yardım miktarlarını karşılaştırma imkanı sağlamaktadır. Aynı zamanda bulguların GSYİH içindeki payları nispetinde karşılaştırılması mevcut durumun daha derin analiz edilmesi imkanını yaratmaktadır. Nitekim literatürde bu yönde daha önce yapılmış herhangi bir bulguya rastlanmamıştır.

Sonuç olarak, enflasyon vergisi miktarlarının incelenen dönemlerin ilk yıllarında genel olarak durağan bir seyir izlediğini, ancak son yıllarda bir artış yaşandığı saptanmıştır. TC yardımları miktarlarının ise yıllar itibariyle iniş çıkışlar gösterse dahi, genel itibariyle artan oranda yükselme seyri izlediği ancak son yıllarda bir azalma eğiliminde olduğu görülmüştür.

Her iki kavram GSYİH içindeki payları nispetinde karşılaştırıldığında ise TC'den gelen yardım miktarlarının GSYIH içindeki payları oranlarının, enflasyon vergisi miktarlarının GSYIH içindeki payları oranlarının çok üstünde olduğu şeklindedir.

\section{Kaynakça}

Ahumada, H., Canavese, A. J., \& Gonzalez Alvaredo, F. (2000). Un análisis comparativo del impacto distributivo del impuesto inflacionario y de un impuesto sobre el consumo. In $V$ Jornadas de Economía Monetaria e Internacional (La Plata, 2000).

Bailey, M. J. (1956). The welfare cost of inflationary finance.Journal of political Economy,64(2), 93110.

Besim, M.(2019). Kuzey Kıbrıs Türk Cumhuriyeti’nde Enflasyon Vergisi Çalışma Kağıdı, Lefkoşa, (26.03.2019)

Bozkurt. (1959,16 Şubat). Kıbrıs Türkleri İktisaden Kalkındırılacaktır. Bozkurt Günlük Müstakil Siyasi Gazete, Sayı 101, Yı1 8, Bozkurt Basımevi, lefkoşa.

DPÖ (2019) TÜFE Verileri http://www.devplan.org/Frametr.html, (04.04.2019) 
Edwards, S. (2001). Dollarization and Economic Performance: An Empirical Investigation. NBER Working Papers, WP 8274, Cambridge, www.nber.org/papers/w8274, (25.06.2002)

Ekinci, A. (2003). Türkiye'de Para Arzının Makroekonomik Değişkenler Üzerine Etkisinin Ekonometrik Analizi: 1990-2002. Dumlupınar Üniversitesi, Sosyal Bilimler Dergisi, 8, 55-68.

Ferrer, C. E. (2012). Seigniorage and inflation tax in Mexico 1985-2011.Rev.Tecsistecatl,4, 13.

Friedman, M. (1971). Government revenue from inflation. Journal of Political Economy, 79(4), 846-856.

Haan, J. D., Zelhorst, D., \& Roukens, O. (1993). Seigniorage in developing countries. Applied Financial Economics, 3(4), 307-314.

Huber, J. (2000, October). Funding Basic Income by Seigniorage. In Basic Income European Network 8th Congress, Berlin pp. 6-7).

Joint Economic Committee Staff Report, (1999). Basics of Dollarization, July 1999, https://www.jec.senate.gov/public/_cache/files/080 20552-766a-42c0-bb83-f4a2f94cbdff/basics-ofdollarization-july-1999.pdf

KEİ Ofisi (2019), TC Kalkınma ve Ekonomik İşbirliği Ofisi, TC Yardımlarl, http://www.kei.gov.tr/media/1817/11-2018-kktcekonomik-goestergeler-raporu.pdf, (03.04.2019)

Kendirci, B. (2013). Türkiye Cumhuriyeti ile Kuzey Kıbrıs Türk Cumhuriyeti Arasında İmzalanan Ekonomik Programlar ve Özellikleri. 2012 Kuzey Kıbrıs Gelecek Vizyonu.
KKTC MB (2019) KKTC Merkez Bankası, Veriler, Para Arzl, http://www.kktcmerkezbankasi.org/tr/veriler/istatis tiki-veriler/para-arzi, $(03.04 .2019)$

Obstfeld, M. (2012). Notes on seigniorage and budget constraints. Economics A, 202, 1-7.

Öner, E. (1994). Vergi-enflasyon ilişkisi ve enflasyon vergisi (1). Atatürk Üniversitesi İktisadi ve İdari Bilimler Dergisi, 10(3-4).

Özen, A. (2018). Dolarizasyon Olgusu: Teorik Bir İnceleme ve Türkiye Örneği. Ekonomi, Politika \& Finans Araştırmaları Dergisi, 3(1), 101-113.

Phelps, E. S. (1973). Inflation in the theory of public finance. The Swedish Journal of Economics, 67-82.

Schuler, K. (1999). "Basics of Dollarization" Joint Economic Committee Staff Report, https://www.jec.senate.gov/public/_cache/files/080 20552-766a-42c0- bb83-f4a2f94cbdff/basics-ofdollarization-july-1999.pdf

Sönmez, S.(1993). Bütçe Açıklarının Finansmanı ve Enflasyon. IX Maliye Sempozyumu Türkiye Bütçe Harcamalart, 6-8 Mayıs 1993, Atakent, Altınorfoz.

TCMB (2013). Enflasyon ve Fiyat Istikrarl, 2013

Ünsal, E. M. (2000). Makro İktisat, İmaj Yayıncılık, 3 Baskı, Ankara.

Yıldırım, Z. R. (1996). Türkiye'de Enflasyon Vergisi Üzerine Bir Deneme. Çukurova Üniversitesi Sosyal Bilimler Enstitüsü Dergisi, 4(4).

Yükseler, Z. (1998). Devlet Planlama Teşkilatı, Y. P. V. K. D. Genel Müdürlüğü, Makro Ekonomik Hesaplar ve Ödemeler Dengesi, Haziran 1998. 